Rev Inv Vet Perú 2003; 14 (2): 155-160

\title{
SEROPREVALENCIA DE Neospora caninum EN LLAMAS DE LA PROVINCIA DE MELGAR, PUNO
}

\author{
Raúl Moya F. ${ }^{1}$, Amanda Chávez V. ${ }^{2,3}$, Eva Casas A. ${ }^{2}$, Enrique Serrano M. ${ }^{2}$, \\ Néstor Falcón P. ${ }^{4}$ y Danilo Pezo C. ${ }^{5}$
}

\section{AbSTRACT}

Neosporosis, caused by the protozoan Neospora caninum, has been associated with reproductive problems in cattle worldwide, and has been found in a variety of animal species, including camels. The aim of this work was to determine the seroprevalence of Neospora caninum in two llama herds of Melgar province, Puno. Two hundred seventy five serum samples of female llamas from the districts of Santa Rosa and Nuñoa were tested using the indirect inmunofluorescense test (IFAT) to detect antibodies against $N$. caninum. The $16.7 \pm 4.4 \%(46 / 275)$ of the serum samples had antibodies at 1:50 dilution, indicating a moderate seroprevalence in the herds. The seroprevalence in Santa Rosa was lower $(4.6 \pm 4.4 \%, 4 / 86)$ than in Nuñoa $(22.2 \pm 5.9 \%, 42 / 189)$, and with statistical differences between herds $(p<0.05)$. No differences due to age were found $(p>0.05)$. This study confirms the presence of Neospora caninum in female llamas from Melgar province, Puno.

Key words: llama, Neospora caninum, IFAT, seroprevalence, antibodies, neosporosis, South American Camelids

\section{RESUMEN}

La neoporosis, causada por el protozoo Neospora caninum, ha sido asociada con problemas reproductivos en la ganadería bovina a nivel mundial, comprobándose que este parásito puede infectar a diversas especies, entre ellos los camellos. El objetivo del presente trabajo fue determinar la seroprevalencia de Neospora caninumen dos centros de crianza de llamas de la provincia de Melgar, Puno. Se evaluaron 275 sueros de llamas hembras en los distritos de Santa Rosa $(\mathrm{n}=86)$ y de Nuñoa $(\mathrm{n}=189)$, mediante la prueba de inmunofluorescencia indirecta. El $16.7 \pm 4.4 \%$ (46/275) presentó anticuerpos contra el parásito a una dilución de 1:50, considerándose como una seroprevalencia moderada. El fundo de Santa Rosa presentó una seroprevalencia baja $(4.7 \pm 4.5 \%, 4 / 86)$, mientras que en el de Nuñoa fue moderada $(22.2 \pm 5.9 \%, 42 / 189)$, existiendo diferencias estadísticas significativas entre ambos fundos $(\mathrm{p}<0.05)$. No se encontraron diferencias significativas entre grupos etáreos ( $\mathrm{p}>0.05$ ). Este estudio confirma la presencia de Neospora caninum en llamas hembras de la provincia de Melgar, Puno.

Palabras clave: llama, Neospora caninum, IFI, seroprevalencia, anticuerpos, neosporosis, camélidos sudamericanos

\footnotetext{
${ }^{1}$ Práctica privada

${ }^{2}$ Laboratorio de Microbiología y Parasitología Veterinaria, FMV-UNMSM

${ }^{3}$ E-mail: a_chavez_g@hotmail.com

${ }^{4}$ Laboratorio de Medicina Veterinaria Preventiva, FMV-UNMSM

${ }^{5}$ Estación Experimental del Centro de Investigación IVITA-Maranganí, FMV-UNMSM
} 


\section{INTRODUCCIÓN}

La crianza de camélidos sudamericanos constituye una actividad económica de gran importancia para un vasto sector de la población andina. La llama, por su mayor tamaño y fortaleza, es utilizado como animal de carga, cumpliendo así un rol importante como medio de transporte en las áreas rurales, además de ser fuente de carne, pieles, cueros y estiércol; esto último usado como fertilizante o combustible. Las llamas son criadas en su casi totalidad por pequeños productores, generalmente carentes de recursos económicos y tecnológicos y bajo sistemas tradicionales no siempre eficaces, que les impiden alcanzar su verdadero potencial productivo (Fernández Bacaet al., 1991). Además, los problemas infecciosos y parasitarios representan las principales limitantes en la cría de estos rumiantes, encontrándose entre ellos los abortos de diversa etiología, y de los cuales se tiene escasa información.

La neosporosis es una enfermedad parasitaria muy difundida en el mundo, siendo reconocida principalmente por su impacto económico en la ganadería lechera al constituir una de las principales causas de aborto y mortalidad neonatal (Dubey, 1999). Es producida por el protozoo Neospora caninum, de morfología similar al Toxoplasma gondii, de la familia Sarcocystidae, del Phylum Apicomplexa (Ortega Mora et al., 1999). La primera descripción de este parásito data de 1984, en Noruega, donde Bjerkas y colaboradores encontraron un parásito similar a Toxoplasma gondii en cerebro y músculo de perros afectados por encefalopatía (Cebrian et al., 2000).

El hospedero definitivo es el perro (Lindsay et al., 1999; McAllister et al.,1998), pero debido a que estos eliminan el parásito por las heces y desarrollan signos de neosporosis, también es considerado un hospedero intermediario (Mc Allister et al., 1998). Se conoce que además infecta a diferentes hospederos intermediarios, entre los que se encuentran los caballos, ovejas, venados, búfalos de agua, coyotes y camellos (Dubey, 1999). En la actualidad, los estudios experimentales de Mc Allister y colaboradores han sido definitivos para el conocimiento de la biología de este parásito (Ortega-Mora et al., 1999). La fase de taquizoito se reproduce asexualmente en el citoplasma de macrófagos, monocitos, hepatocitos y otras células, mientras que en su fase quística este protozoo sólo parasita el SNC, médula espinal, nervios y la retina, ocasionando trastornos neuromusculares en perros cachorros y otros animales recién nacidos (Dubey y Lindsay, 1996). El perro se infecta al ingerir los quistes tisulares que se hallan en los restos de hospederos intermediarios, en fetos abortados y placentas; y los hospederos intemediarios se infectan al ingerir agua y alimentos contaminados con ooquistes (Ortega Mora et al., 1999). En bovinos, la evidencia sugiere que la principal ruta de transmisión es la vertical, con una eficiencia mayor al $80 \%$ (Anderson et al., 1997).

La infección por Neospora caninum ha sido diagnosticada en numerosos países del orbe (Ortega Mora et al., 1999). En el Perú, estudios realizados en 1993 por Rivera en la cuenca lechera de Santa Rita en Arequipa, establecieron la existencia de animales seropositivos aNeospora caninum con una tasa de infección del 57\% (Andresen, 1999), confirmándose posteriormente su presencia en la cuenca lechera de Lima (Silva, 2002) y en Amazonas (Quevedo, 2003). Sin embargo, la información sobre Neospora caninum sigue siendo escasa, siendo necesarios más estudios epidemiológicos que permitan conocer la prevalencia de este parásito en otras especies, incluyendo los camélidos sudamericanos. Si bien no hay estudios previos en camélidos sudamericanos, este parásito ha sido reportado en camellos (Hilali et al., 1998), por lo que el objetivo del presente trabajo fue determinar la seroprevalencia de Neospora caninum en llamas hembras de dos hatos de investigación de la provincia de Melgar, Puno. 


\section{Materiales y Métodos}

\section{Lugar de estudio y animales}

El muestreo se realizó en el Centro Experimental de Machuwasi de la Universidad San Antonio Abad del Cuzco y en el fundo San Luis del Instituto de Investigaciones Tropicales y de Altura (IVITA) de la Universidad Nacional Mayor de San Marcos. Ambos se hallan localizados en la provincia de Melgar, departamento de Puno, a una altitud aproximada de $4200 \mathrm{msnm}$, con una temperatura media que oscila entre 0 y $15^{\circ} \mathrm{C}$ durante el día y con una precipitación media anual que va de 250 a $500 \mathrm{~mm}$ (Moreno et al., 1998).

El centro experimental de Machuwasi tenía una población de 670 llamas, de las cuales 423 eran hembras, mientras que el fundo de San Luis tenía una población de 410 llamas, de las cuales 262 eran hembras.

\section{Muestras y análisis de laboratorio}

El tamaño muestral $(n=247)$ se determinó mediante la fórmula de poblaciones finitas (Daniel, 1996), utilizándose para su cálculo una proporción anterior (desconocida) de 0.5 y un nivel de confianza de $95 \%$.

Se trató de estratificar el tamaño muestral según la población de llamas de cada hato, pero debido a restricciones logísticas ocurridas en el Centro Experimental de Machuwasi, sólo se pudo muestrear 86 animales de ese hato, completándose la muestra con 189 animales procedentes del fundo San Luis.

Las muestras de sangre fueron obtenidas por punción directa de la vena yugular, extrayéndose una muestra de $5 \mathrm{ml}$ de sangre en tubos vacutainer, los cuales se dejaron en reposo y luego fueron centrifugados para extraer el suero. Estos se depositaron en viales de $2.5 \mathrm{ml}$ y se conservaron en congelación $\left(-20^{\circ} \mathrm{C}\right)$ hasta su procesamiento en el Laboratorio de Parasitología de la Facultad de Medicina Veterinaria de la UNMSM.
Las muestras se analizaron mediante la prueba de inmunofluorescencia indirecta (IFI) utilizada por Tress et al. (1993), siendo modificada en los laboratorios de Parasitología de la Universidad Complutense de Madrid y de la Facultad de Medicina Veterinaria de la UNMSM, Lima.

Los sueros de llamas fueron diluidos en 1:50, utilizándose como antígeno a taquizoítos formolizados (cepa Nc-1) y conjugado comercial VMRD-USA. Las muestras fueron consideradas positivas si se observó fluorescencia en todo el contorno del parásito, o negativas si no hubo fluorescencia o ésta fue parcial. El punto de corte fue de 1:50.

\section{Análisis estadístico}

Se estimó la seroprevalencia (Thrusfield, 1990) de Neospora caninum y el intervalo de confianza (Armitage y Berry, 1987) corrrepondiente, cuantificándose la asociación entre la zona geográfica, la edad y la presencia de anticuerpos contra $N$. caninum mediante la prueba de regresión logística, usando el programa SPPS 10.0.

\section{Resultados y Discusión}

La seroprevalencia de $N$. caninum en llamas hembras fue de $16.7 \pm 4.4 \%$, (46/275) mediante la prueba de IFI (Cuadro 1). Este hallazgo nos indicaría que estos animales estuvieron expuestos al parásito en algún momento de sus vidas, ya sea en la etapa pre o postnatal.

Entre los factores que pueden contribuir a la presencia y transmisibilidad del parásito entre estos animales se encuentra la explotación extensiva mixta que se realiza en la zona con otros hospederos intermediarios, como el ganado vacuno, principal hospedero intermediario que se ve afectado por este parásito. La presencia de canes en los alrededores constituye otro factor de riesgo ya que 
R. Moya et al.

Cuadro 1. Seroprevalencia de Neospora caninum en llamas hembras de dos fundos ganaderos en la provincia de Melgar, Puno. 2002

\begin{tabular}{lccc}
\hline Fundos Ganaderos & Animales muestreados & Animales seropositivos & $\% \pm$ IC $^{1}$ \\
\hline San Luis & 189 & 42 & $22.2 \pm 5.9$ \\
Machuwasi & 86 & 4 & $4.7 \pm 4.5$ \\
\hline Total & 275 & 46 & $16.7 \pm 4.4$ \\
\hline
\end{tabular}

${ }^{1}$ Intervalo de confianza del 95\%

Cuadro 2. Detección de anticuerpos contra Neospora caninum en llamas hembras de dos fundos ganaderos en la provincia de Melgar, Puno, según grupos etarios. 2002

\begin{tabular}{|c|c|c|c|c|}
\hline \multirow[b]{2}{*}{ Edad (años) } & \multicolumn{2}{|c|}{ San Luis } & \multicolumn{2}{|c|}{ Machuwasi } \\
\hline & $\begin{array}{c}\text { Animales } \\
\text { muestreados }\end{array}$ & $\% \pm$ IC & $\begin{array}{c}\text { Animales } \\
\text { muestreados }\end{array}$ & $\% \pm \mathrm{IC}$ \\
\hline$<1$ & 44 & 29.6 & 0 & 0 \\
\hline 2 a 4 & 76 & 21.1 & 26 & 0 \\
\hline 5 a 8 & 44 & 15.9 & 30 & 3.3 \\
\hline$>8$ & 25 & 24.0 & 30 & 10.0 \\
\hline Total & 189 & $22.2 \pm 5.9$ & 86 & $4.6 \pm 4.5$ \\
\hline
\end{tabular}

estos contaminan el agua y las áreas de pastoreo con ooquistes. Un factor de alto riesgo podría ser la introducción de llamas infectadas provenientes de otras zonas, pero esta posibilidad no existió en este caso por tratarse de hatos cerrados.

La diferencia observada entre ambos hatos podría deberse a una mayor presencia de perros en el área de San Luis. Ambos hatos son manejados bajos sistemas tradicionales de crianza extensiva. Es así que, en el hato de San Luis, los pastores poseen perros, los cuales están en contacto directo con las llamas teniendo acceso libre a todos los lugares donde se encuentran, incluyendo las canchas de parición. Estudios realizados en bovinos han comprobado que existe una estrecha relación entre la presencia del parásito en hatos donde hay perros frente a hatos sin ellos (Wouda et al., 1999). Otro factor importante a tomar en cuenta por el tipo de manejo, sería la presencia de cánidos silvestres en la zona, específicamente de zorros, ya que es posible la existencia de un ciclo de transmisión silvestre de $N$. caninum (Barling et al., 2000).

La zona altoandina se caracteriza por tener una crianza extensiva mixta de camélidos con otras especies, tales como ovinos y bovinos. En estas especies, especialmente en bovinos, ha sido documentada la infección por $N$. caninum. La estrecha convivencia de estas especies con el perro facilitaría que se desarrolle la transmisión horizontal, ya que estos no tienen ninguna restricción a los restos de placentas, fetos abortados y descar- 
gas uterinas; medios por los cuales se infectarían (Dijkstra et al., 2002). Los perros, al tener acceso a los campos de pastoreo, los estarían contaminando con las heces.

Al utilizar la prueba de regresión logística, para comparar los resultados de ambas zonas, se encontró diferencias estadísticas significativas entre ambos fundos ganaderos ( $\mathrm{p}<0.05)$, estableciéndose que existe un mayor riesgo de exposición en San Luis porque existe una mayor prevalencia del parásito respecto al Centro Experimental de Machuwasi (OR: 5.656).

Respecto a la edad, los resultados de la regresión logística indicaron, que no existieron diferencias estadísticas significativas entre los distintos grupos etarios (Cuadro 2). Por tanto, con las evaluaciones realizadas, no pudo establecerse cual sería la posible vía de transmisión (horizontal o vertical) de este parásito.

Es necesario anotar que si bien los índices promedio de productividad en llamas son bastante bajos (45\% de natalidad y $30 \%$ de mortalidad en crías, Raggi, 1992), el hallazgo de anticuerpos contra $N$. caninum en el presente estudio, no confirmaría que este parásito sea causa de problemas reproductivos, sino sólo que ha existido exposición a él. Los resultados confirman la presencia del parásito en llamas, siendo necesario realizar más estudios que determinen la implicancia de Neospora caninum como causante de problemas reproductivos en llamas y camélidos sudamericanos en general.

\section{Conclusiones}

- El $16.7 \pm 4.4 \%$ de las llamas de dos hatos de centros de investigación de la provincia de Melgar, Puno, fueron positivas al parásito Neospora caninum mediante la prueba de inmunofluorescencia indirecta.
- Las prevalencias entre rebaños de llamas fueron estadísticamente diferentes entre sí ( $\mathrm{p}<0.05)$.

- No se encontraron diferencias estadísticas significativas entre grupos etáreos.

- Se requiere de estudios adicionales que permitan determinar la verdadera implicancia de $N$. caninum como agente causal de problemas reproductivos en camélidos sudamericanos.

\section{Literatura Citada}

1. Anderson, M.L.; J.P. Reynolds; J.D. Rowe. 1997. Evidence of vertical transmission of Neospora sp. infection in dairy cattle. J. Am. Vet. Med. Assoc. 210: 1169.

2. Andresen, H. 1999. Neosporosis en el Perú y el Mundo. Rev. Cienc. Vet. 15: 11-14, 30-31.

3. Armitage, P.; G. Berry. 1987. Statistical methods in medical research. $2^{\text {nd }}$ ed. $p$ 115-120. Blackwell Scientific Publ. U.K.

4. Barling, K.S.; M. Sherman; M.J. Peterson; J.A. Thompson; J.W. McNeill; T.M. Craig; L.G. Adams. 2000. Spatial association among density of cattle, abundance of wild canids, and seroprevalence to Neospora caninum in a population of beef calves. J. Am. Vet. Med. Assoc. 217: 1361-1365.

5. Cebrian, L.M.; M. Barberan; L.M. Ferrer. 2000. Neosporosis y aborto en el ganado vacuno. Prod. Anim. 15: 1526.

6. Daniel, W. 1996. Bioestadística: base para el análisis de la ciencia de la salud. $5^{\text {ta }}$ ed. p 205-207. Ed. Limusa. México.

7. Dijkstra, T.; H.W. Barkema; M. Eysker; J.W. Hesselink; W. Wouda. 2002. Natural transmission routes of Neospora caninum between farm dogs and cattle. Vet. Parasitol. 105: 99-104.

8. Dubey, J.P; D.S. Lindsay. 1996. A review of Neospora caninum and neosporosis. Vet. Parasitol. 67: 1-59. 
9. Dubey, J.P. 1999. Recent advances in Neospora and neosporosis. Vet. Parasitol. 84: 349-367.

10. Fernández Baca, S.; J.F. Chávez; E.R. Flores; G. Leguía; C. Novoa; A. Ramírez; F. San Martín; J. Sumar; A. Vallenas; M.A. Vilca; J. Villaroel; J.C. Wheeler. 1991. Avances y perspectivas en el conocimiento de los camélidos sudamericanos. Oficina Regional de Producción Animal, FAO. Santiago, Chile. 429 p.

11. Hilali, H.; J.P. Dubey; S. Romand; P. Thulliez; O.C.H. Kwok. 1998. Prevalence of Neospora caninum and Toxoplasma gondii antibodies in sera from camels from Egypt. Vet. Parasitol. 75: 269-271.

12. Lindsay, D.; J.P. Dubey; R. Duncan. 1999. Confirmation that the dog is a definitive host for Neospora caninum. Vet. Parasitol. 82: 327-333.

13. McAllister, M.M.; J.P. Dubey; D.S. Lindsay; W.R. Jolley; R.A. Wills; A.M. McGuire. 1998. Dogs are definitive hosts of Neospora caninum. Int. J. Parasitol. 28: 1473-1478.

14. Moreno, E.; A. Canales; L. Flores; D. Pineda; D. Araníbar. 1998. Punto Focal: Puno. Estrategia regional para la conservación y utilización sostenible de la diversidad biológica. Consejo Nacional del Ambiente (CONAM). $55 \mathrm{p}$.

15. Ortega-Mora, L.M.; A. Alonso; G. Álvarez; E. Collantes; J.M. Corpa; C. Frisuelos; M. Gómez-Bautista; L. Mar- tín; G. Miró; J. Pereira Bueno; V. Pérez; A. Quintanilla-Gozalo; L. Del Río-Gonzáles. 1999. Patología de la reproducción de etiología parasitaria (II): Neosporosis. Rev. Aula Veterinaria Bovis 88: 1-86.

16. Quevedo, M. 2003. Neosporosis en bovinos lecheros en dos distritos de la provincia de Chachapoyas. Tesis de Médico Veterinario. Facultad de Medicina Veterinaria, Univ. Nacional Mayor de San Marcos. Lima, Perú. 58 p.

17. Raggi, L. 1992. Camélidos: una opción ganadera. El Campesino 123: 16-23.

18. Silva, P. 2002. Seroprevalencia de Neospora caninum en bovinos lecheros del valle de Lima. Tesis de Médico Veterinario. Facultad de Medicina Veterinaria, Univ. Nacional Mayor de San Marcos. Lima, Perú. 42 p.

19. Thrusfield, M. 1990. Epidemiología veterinaria. p 228-230. Ed. Acribia. Zaragoza, España.

20. Trees, A.; F. Guy; B. Tennant; A. Balfour; J.P. Dubey. 1993. Prevalence of antibodies to Neospora caninum in a population of urban dogs in England. Vet. Rec. 132: 125-126.

21. Wouda, W; T. Dijkstra; A.M.H. Kramer; C. van Maanen; J.M.A. Brinkhof. 1999. Seroepidemiological evidence for a relationship between Neospora caninum infection in dogs and cattle. Internat. J. Parasitol. 29: 16771682. 